\title{
Three Phase Enhanced Electrical Energy Metering System
}

\author{
ALI M. EL-RIFAIE, BILEL NEJI, IMAD NEJDAWI \\ College of Engineering and Technology \\ American University of the Middle East \\ Egaila, \\ KUWAIT
}

\begin{abstract}
This pap er presents a practical solution for two existing problems in traditional electrical e nergy measurements. The first problem is the manual electrical billing system; so far, some countries are still adopting a manual technique with a high percentage of human errors and much complains from the consumers' side and a lot of work from the authorities' side. The second problem is having a low power factor at most of the domestic loads and some main commercial ones. Low power factor causes more current to flow in the network leading to an overheating of transformers and cables, and an increase of the core losses of transformers; in addition, less power factor means more burned fuel and more environment pollution. In This study, an automated solution for both problems is introduced, where two control units are added to the already existing three phase energy meters. The first unit solves the problem of manual billing by automatically calculating the monthly bill and sending monthly SMS messages to the consumers as well as authorities. The second unit solves the problem of low power factor by injecting reactive power using capacitor bank at the end load points to maintain a power factor of 0.95 at all load cases. A penalty will be added to the monthly calculated bill once the above value is violated. A prototype was implemented proving the capability of introducing both solutions using existing meters with a reasonable added cost.
\end{abstract}

Keywords: Smart Metering, Power Factor, Electricity bill, Raspberry pi, Energy meters, Capacitor bank Received:

September 30, 2019. Revised: April 27, 2020. Accepted: May 12, 2020. Published: June 7, 2020

\section{Introduction}

Some countries especially those who are gifted with much fuel are still using fossil fuel as a source of heat energy in power stations to produce electricity. Since the renewable energy resources in tho se countries are quite limited, leaving this process poorly supervised or monitored will create a lot of problems in the future [12]. Since the demand for power is increasing every day, due to the increase of population in the last recent years, urgent actions should be taken regarding preserving and protecting this source to last longer than anticipated. S o far, some countries are still using a manual electrical energy billing system, and that could result in loss of revenues. This loss mainly comes due to measurement errors, calculation errors, as well as lack of confidence between consumers and authorities. To solve this problem, many countries started using smart electrical energy meters as they have much higher capabilities compared to the traditional ones [35]; however, its high cost, expensive infrastructure, complicated technology, in addition to electricity theft and sudden electricity cutoff, still act as strong barriers toward replacing traditional meters with smart and prepaid ones. An economic solution could be enhancing the traditional energy meters to give it the capability of having an a utomated billing system in addition to some other needed features [6-10].
These enhancements would allow the existing energy meters to perform in an ad vanced way, save a lot of money and time, and avoid a lot of technical complications.

At a basic level, the power factor of an electrical device could be defined as the ratio of power drawn by the device from the main supply to the ac tual power consumed by the device. An electric or electronic device is said to be ideal if it $\mathrm{c}$ an consume all the power that it draws. In other words, an ideal device has got unity power fac tor. A nonlinear load with poor power factor will generate harmonics. Harmonics and poor power factor have got many undesirable effects. The continuous use of nonlinear loads in domestic side is rapidly increasing and that would result in lowering the power factor and increasing network losses [11-14]. Enhancing the power factor at the end load points will minimize the overall current in the electrical network leading to less magnetic losses, less fuel consumption, and less air pollution. In this paper, an enh anced three ph ase electrical energy metering system is intro duced, where a microcontroller with two units is added to the already existing three phase electrical energy meters. The first unit solves the problem of manual billing by automatically calculating the monthly bill and sending monthly SMS messages to consumers and ministry of 
electricity. The second unit solves the problem of low power factor by injecting reactive power using capacitor bank at the end load points to maintain a power factor of 0.95 at all load cases. A penalty will be added to the monthly calculated bill once the above-mentioned value is violated. A prototype was implemented and the capability of introducing both solutions using existing meters with a limited added cost was demonstrated.

\section{Proposed System and Design}

The main goals of the proposed solutions are to enhance the existing measuring system, and to avoid any interruption, extra cost, and technical problems. The fact that the used electrical energy meters will vary between electromechanical energy meters and electronic ones makes it necessary to implement a system that can deal with any meter regardless of its measuring technique [15]. The proposed solution relies on adding a microcontroller unit to the existing energy meter. The energy meter $\mathrm{KWH}$, and KVARH measurements are fed to the microcontroller using a scan head or pulse cou nter for mechanical and electronic meters respectively. The microcontroller will do all the calculations and take the necessary actions based on the received measurements.

Figure 1 shows the connection of the microcontroller with two parallel units to an electronic electrical energy meter.

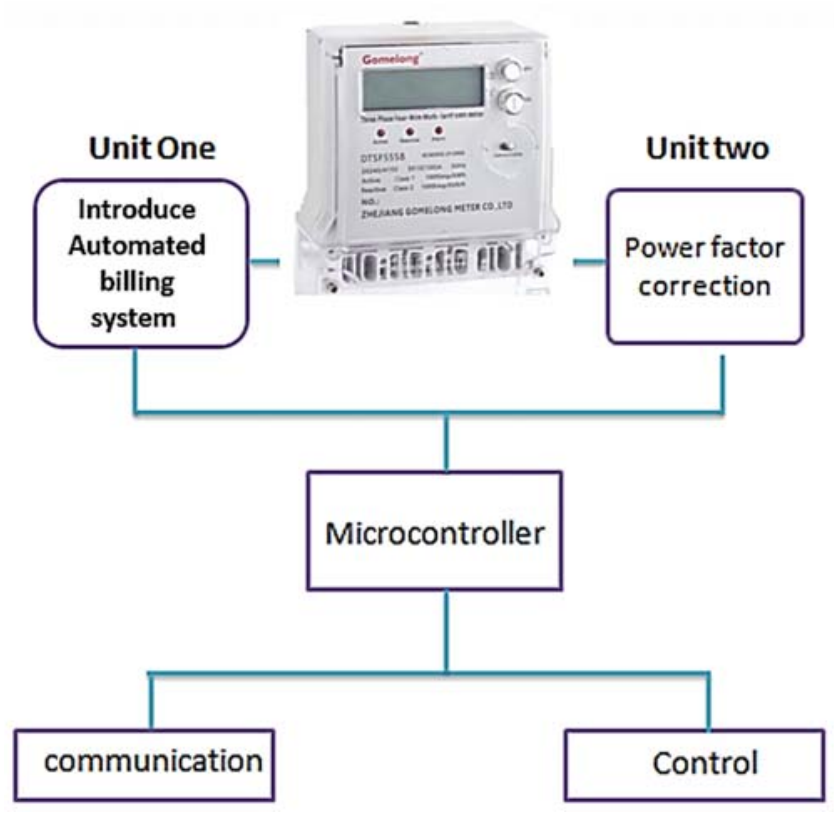

Figure 1. proposed microcontroller-based system Unit one is directly connected to a GSM and its main function is to estimate the monthly bill and share it with the consumer on a monthly basis. Unit two is monitoring the power factor and controlling a capacitor bank to keep the power factor value within the assigned limits.

\subsection{Automatic Bill Calculation-Unit one}

This unit has three functions: estimate the monthly KWHR consumption, calculate the monthly bill amount, and communicate the calculated amount to the authorities and the consumer. This unit consists of an electrical energy meter and an Arduino mega. The meter pulses are fed to Raspberry Pi 3 microcontroller [16] and counted using the built-in interrupt function. The KWH monthly consumption is calculated following equation 1 .

$\mathrm{KWH}=$ monthly received pulses $\times$ meter constant $(1)$

The monthly bill is calculated following equation 2 .

$$
\text { Monthly bill cost }=\mathrm{KWH} \times \mathrm{A}
$$

Where the residential consumers' tariff is assumed to be A $\$ / K W H$.

In addition, the system can b e programmed for different consumer categories with different tariffs if needed, including domestic, commercial and industrial loads.

Communication is performed using a GSM module which is used for sending SMS messages to consumers' registered mobiles as well as responsible authorities' database.

The message sent to a uthorities includes a code describing the user's personal information such as the meter's serial number, his name, his phone number, his home address, and the bill amount. Using such system, the authorities will no longer need to send a worker to manually check the meter readings, and a lot of paperwork will be a voided and that minimizes the chances of having possible errors in bill calculation.

One more function of this unit is to send notifications to both authorities and consumers whenever the power factor value is not meeting the assigned one. In this case consumers will be aware of any additional penalties they have to pay for violating the PF value, while authorities will have the chance to provide any 
needed technical support to guarantee highest efficiency, stable network with suitable current flow without cables overheating, least transformers core losses and minimum amount of burned fuel.

\subsection{Power Factor Control-Unit two}

The aim of this unit is to measure and enhance the power factor at domestic load ends. This will req uire adding capacitor banks that should be smartly controlled to ensure non-violation of $\mathrm{P}$ ower factor limits at all loading conditions. In addition, since the power factor value is determined in most countries to exceed 0.90 , this unit will ensure that whoever has a lower power factor pays an extra penalty via sending an SMS to the consumer and the previously mentioned SMS code to the ministry. The penalty will vary as follows: when the power factor

is slightly lower than allowed; in this case, the user will only receive a warning by SMS and will be given a specific period to improve the $\mathrm{p}$ ower factor by connecting a new capacitor bank or fixing the existing one.

The second case is when the user's power factor is low; in this case, the user will pay an extra percentage of the bill as a penalty and will be given time to improve the po wer factor. The 1 ast case is when the power factor is too low; in this case, the user will pay double the bill and will be giv en a sho rt time to improve the power factor. Power Factor (PF) calculation is done using equations 3,4 and 5 . Figure 2 shows a simple description for the operation of Unit 2. The shown penalty is just an example.

$\mathrm{KVARH}=$ monthly received pulses $\times$ reactive constant ..(3) $\mathrm{KVAH}=\sqrt{\mathrm{KWH}^{2}+\mathrm{KVARH}^{2}}$

$$
\mathrm{PF}=\frac{\mathrm{KWH}}{\mathrm{KVAH}}
$$

TABLE-1- list of equipment used in prototyping

\begin{tabular}{cc}
\hline Component & Description \\
Raspberry Pi 3 & $\begin{array}{c}\text { microcontroller coded using } \\
\text { python }\end{array}$ \\
\hline GSM module & $\begin{array}{c}\text { Used for communication with } \\
\text { the user and authorities }\end{array}$ \\
\hline $\begin{array}{c}\text { Three phase } \\
\text { digital energy } \\
\text { meter }\end{array}$ & $\begin{array}{c}\text { Electronic with KWHR and } \\
\text { KVARH measurements. }\end{array}$ \\
\hline Circuit Breaker & Used for protection and switching \\
\hline Contactor & To Control the capacitor bank. \\
\hline Capacitor Bank & $\begin{array}{c}\text { Fixed and variable values to } \\
\text { enhance the power factor. }\end{array}$ \\
\hline Three phase & $\begin{array}{c}\text { used as a load with variable } \\
\text { mechanical load 1450 rpm, 1.5 } \\
\text { Induction motor and 400V }\end{array}$ \\
\hline
\end{tabular}

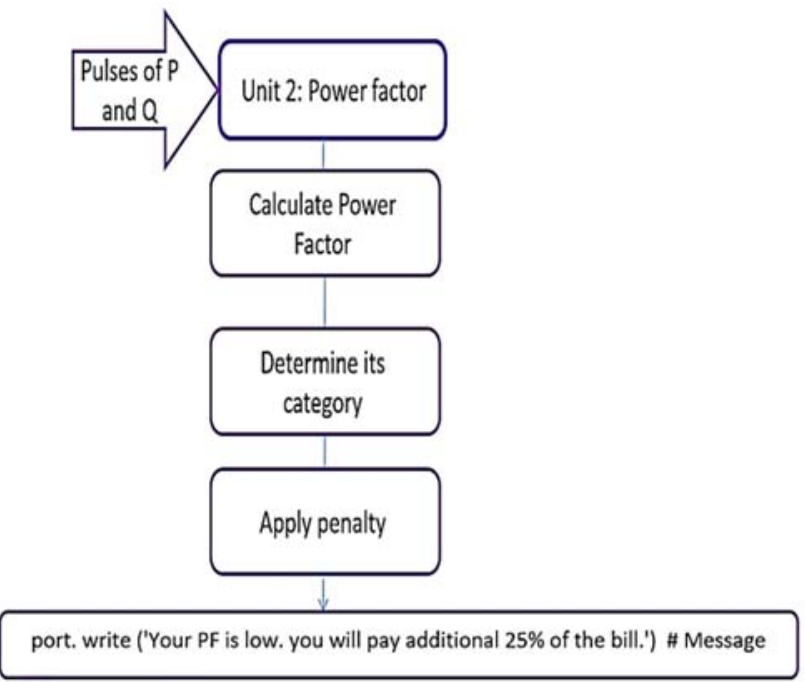

Figure 2. Operation sequence of unit 2

\section{Prototype and System Evaluation}

To demonstrate the capability of both units, a prototype is designed using a three-phase induction motor as a load. TABLE-1 shows the main components and the elements used to implement the prototype.

Figure 3 sho ws a schematic diagram of the implemented prototype where both units are tested under different loading conditions. Unit one SMS messages samples are sh own in Figure 4. The messages to be sent have different formats based on the receiver's preferences, for consumer the monthly bill amount is stated clearly, however a cod e is generated, in the case it is sent to authorities, to give full details based on the data base $\mathrm{p}$ reference and requirements. The generated code includes the month, year, meter unique ID and monthly bill.

Figure 5 shows a sample of the measured PF during no load $\mathrm{w}$ ith and without PF correction, a fi xed capacitor of $6.2 \mu \mathrm{F}$ per phase was used for demonstration. During normal operation, a capacitor bank of different capacitor values should be used to avoid any overcompensation. In this case unit two will be trained to achieve such a task.

TABLE-2 shows the change in PF values during some load conditions, the increase in PF value is noticeable, 
however the needed threshold value was not attained as only fixed value capacitors were used for demonstration. In re al applications a capacitor bank with several capacitance values should be $u$ sed to guarantee having the op timum power factor va lue during all load conditions. Samples of unit one messages in case of PF penalty are shown in Figure 6.

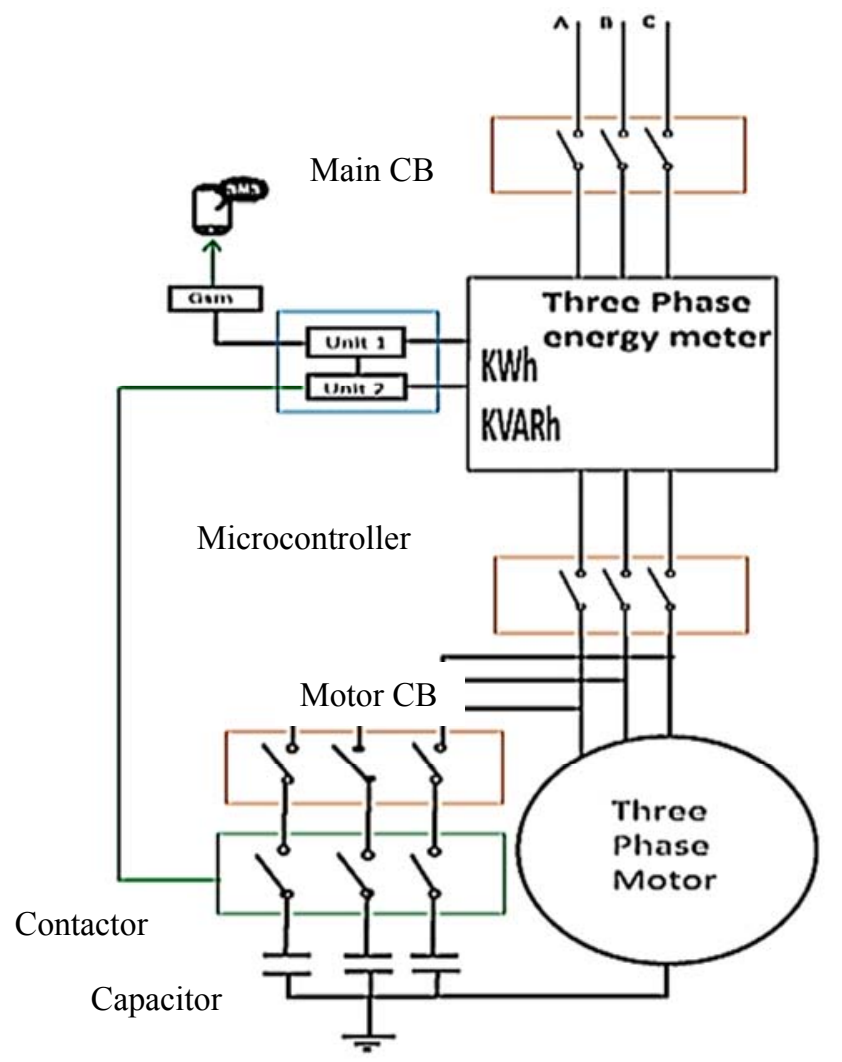

Figure 3. Prototype Construction
Your Monthly electricity bill for December 2019 is $66 \$$ Please settle your bill using: consumer.mee.gov your meter ID is: 1125761283

(a)

\section{$1219-1125761283-066$}

(b)

Figure 4. (a) message sent to consumer, (b) code sent to authorities data base

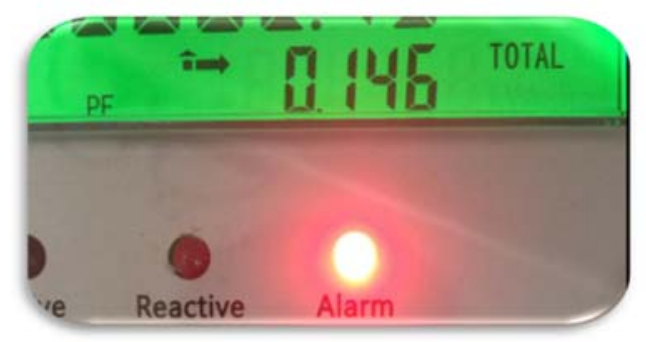

(a)

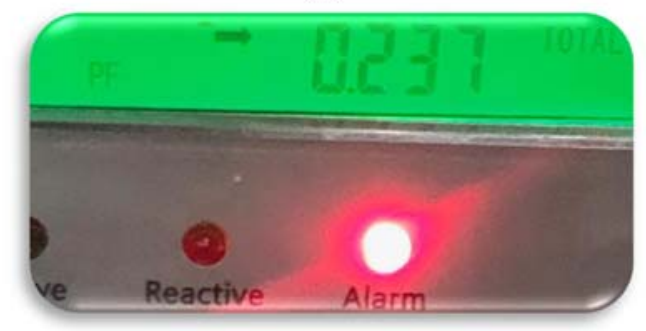

(b)

Figure 5. Measured PF value during no load condition (a) without capacitor, (b) with capacitor 
TABLE-2- PF values during different loading conditions

\begin{tabular}{ccc}
\hline $\begin{array}{c}\text { Load } \\
\text { condition }\end{array}$ & $\begin{array}{c}\text { Without } \\
\text { Capacitors }\end{array}$ & $\begin{array}{c}\text { With } \\
\text { Capacitors }\end{array}$ \\
\hline No Load & 0.146 & 0.237 \\
\hline 25\% Load & 0.298 & 0.401 \\
\hline Half Load & 0.421 & 0.558 \\
\hline $75 \%$ Load & 0.689 & 0.810 \\
\hline Full Load & 0.800 & 0.891 \\
\hline
\end{tabular}

Your Monthly electricity bill for December 2019 is $66 \$$ Added PF Penalty: $10 \$$

Please settle your total bill of $76 \$$ using: consumer.mee.gov your meter ID is: 1125761283

(a)

\section{9-1125761283-066-PF010_T076}

(b)

Figure 6. (a) Message sent to customer with PF penalty (b) message sent to authorities with PF penalty

\section{Conclusion}

This paper in troduced an enhancement simple three phase electrical measuring system, the enhanced system uses the existing energy meter; in add ition a microcontroller is added to the existing digital energy meter to ob tain an au tomated billing system and guarantee a minimum power factor of 0.95 . Automatic billing will result in reducing unnecessary jobs, besides minimizing billing errors. Having all loads with a minimum power factor of 0.95 will increase the lifespan of the electrical network components, reduce magnetic core losses of transformers, and re duce environment pollution as we need to burn less fuel. A three-phase prototype is implemented to demonstrate the idea. The main contribution of thi $\mathrm{s}$ proposed system is that it is using all the existing equipment without implementing a ne $\mathrm{w}$ infrastructure that consumes a lo $t$ of money as well as time. Results showed full success of the proposed methodology to fulfill its assigned task. The overall cost of the proposed prototype is around $25 \$$.

\section{References}

[1] N. Abas, A. Kalair, N. Khan "Review of fossil fuels and future energy technologies" Futures, Volume 69, May 2015, Pages 31-49

[2] Florinda Martins, Carlos Felgueiras, Miroslava Smitkova, and Nídia Caetano "Analysis of Fossil Fuel Energy Consumption and Environmental Impacts in European Countries" Energies 2019, 12, 964; doi:10.3390/en12060964

3] Bimenyimana, Samuel \& Asemota, Godwin. "Traditional Vs Smart Electricity Metering Systems: A brief overview" Journal of Marketing and Consumer Research 2018, volume 46.

4] Azfar Tufail and Hummayoun Naeem "Advance Energy Management through Smart Metering System: An Operational Perspective" Journal of Electrical and Electronics Engineering (IOSRJEEE) e-ISSN: 2278-167 6, p-ISSN: 2320-3331, Volume 11, Issue 3 Ver. II (May. - Jun. 2016), PP 01-13

[5] Noelia Uribe-Pérez, Luis Hernández, David de la Vega and Itziar Angulo "State of the Art and Trends Review of Smart Metering in Electricity Grids” Appl. Sci. 2016, 6, 68; doi:10.3390/app6030068

[6] Rana, Zahid Iqbal \& Waseem, Muhammad and Mahmood, Tahir. (2014). "Automatic Energy Meter Reading using Smart Energy Meter" 10.13140/RG.2.1.1343.7928.

[7] Okokpujie, Kennedy, Adebayo, Abayomi-Alli, Abayomi-Alli, Olusola Odusami, Modupe, Okokpujie, Imhade, and Akinola, O.A. "An Automated Energy Meter Reading System Using Gsm Technology". $2^{\text {nd }}$ International Conference on Applied Information Technology 2017

[8] Abinayam, Abiramig, Abiramim, Gayathrik, Sobana K "Automatic Meter Reading for Electricity Consumption and Billing System using Plcc" International Journal of Engineering Trends and Technology (IJETT) - Volume 57 Number 1 March 2018

[9] Bhakthavathsalam R, Saqquaf S. M., Chaithra P. S., Gireesh P. G., Ravindraa K. N "Zigbee Based Energy Monitoring System with E-Billing through GSM Network" International Journal of Innovative Research in Electro nics and Communications (IJIREC) Volume 1, Issue 5, August 2014, PP 1-12 
[10] Ali M. El-Rifaie, Imad M. Nejdawi, Zaher Al Barakeh "Automatic Billing System for Classical Electrical Energy Meters" International Journal of Engineering and Technical Research (IJETR) ISSN: 2321-0869 (O) 2454-4698 (P) Volume-9, Issue-8, August 2019

[11] Silpa Thomas, Anjali Shalimar, Unnikrishnan L "An Overview of Power Factor Improvement Techniques in Domestic and Industrial Loads" 2015 IJSRSET Volume 1, Issue 1 Print ISSN: 2395-1990 | Online ISSN : 2394-4099

[12] Bilal Naji Alhasnawi, Basil H.Jasim "Automated Power Factor Correction for Smart Home" Iraqi Journal of Electrical and Electronic Engineering, Volume 14, No. 1- 2018

[13] V.C. Eugin Martin Raj and S. Lese "A Novel Approach for Power Factor Correction Using Microcontroller in Domestic Loads" Middle-East Journal of Scientific Research 24 (4): 1042-1046, 2016 ISSN 1990-9233 2016

[14] Ali, Waqas \& Farooq, Haroon \& Jamil, Mohsin \& Rehman, Ata \& Taimoor, Rana \& Ahmad, Monib. (2018). "Automatic Power Factor Correction for Single Phase Domestic Loads by Means of Arduino Based TRIAC Control of Capacitor Banks” 72-76. 10.1109/ECE.2018.8554986.

[15] áceres, Roberto \& Correa, Roberto \& Ferreyra, Pablo \& Cordero, Eduardo. (2006). "Study of Active Electric Energy Meters Behavior of Induction and Electronic Types". 1 - 6. 10.1109/TDCLA.2006.311557.

[16] Python.org. (2018). Welcome to Python.org. [Online] Available at: https://www.python.org 